\title{
The levonorgestrel intrauterine device in Australia: analysis of prescribing data 2008- 2012
}

\author{
Amie L. Bingham ${ }^{1 *}$ D, Cameryn C. Garrett ${ }^{1}$, Christine Bayly ${ }^{2}$, Anne M. Kavanagh', Louise A. Keogh ${ }^{1}$, \\ Rebecca J. Bentley ${ }^{1}$ and Jane S. Hocking ${ }^{3}$
}

\begin{abstract}
Background: Unplanned pregnancy is a significant problem in Australia. Local data pertaining to use of the levonorgestrel-releasing intra-uterine device (LNG-IUD), and associated factors are limited. The aim of this analysis was to calculate prescribing rates of the LNG-IUD in Australia, including trends in prescribing and associations with socio-demographic factors, in order to increase understanding regarding potential use.

Methods: We examined prescriptions for the LNG-IUD recorded in the national Pharmaceutical Benefits Scheme (PBS) from 2008 to 2012. Prescribing trends were examined according to patient age, remoteness of residential location, and proximity to relevant specialist health services. Associations between these factors and prescription rates were examined using poisson regression. Analyses were stratified by 5-year age-groups.

Results: Age-adjusted prescription rates rose from 11.50 per 1000 women aged 15-49 (95\% Cl: 11.41-11.59) in 2008 to 15.95 (95\% Cl:15.85-16.01) in 2012. Prescription rates increased most among 15-19-year-olds but remain very low at 2.76 per 1000 women (95\% Cl: 2.52-3.01). Absolute increases in prescriptions were greatest among 40-44-year-olds, rising from 16.73 per 1000 women in 2008 (95\% Cl: 16.12-17.34) to 23.77 in 2012 (95\% Cl: 22.58-24.29). Rates increased significantly within all geographical locations $(p<0.01)$. Non-metropolitan location was significantly associated with increased prescribing rates, the association diminishing with increasing age groups.

Conclusions: Prescription of LNG-IUD in Australia is very low, especially among young women and those in major cities. Service providers and young women may benefit from targeted education outlining use of the LNG-IUD, strengthened training and referral pathways. Disparities in prescription according to location require further investigation.
\end{abstract}

\section{Introduction}

The levonorgestrel-releasing intrauterine device (LNG-IUD) is a highly effective long-acting reversible contraceptive (LARC). While shorter-acting contraceptives such as the oral contraceptive pill require high levels of patient compliance to maintain effectiveness, the LNG-IUD is effective for up to 5 years, with a first-year failure rate similar to that of sterilisation $(0.2 \%)$ [1]. It is cost-effective and suitable for the vast majority of women $[1,2]$. While pain and changing bleeding patterns are common causes of discontinuation,

\footnotetext{
* Correspondence: binghama@unimelb.edu.au

${ }^{1}$ Centre for Health Equity, Melbourne School of Population \& Global Health, University of Melbourne, 207 Bouverie Street, Carlton 3010, Australia Full list of author information is available at the end of the article
}

reduced bleeding and amenorrhoea are considered benefits by many: the LNG-IUD can be used to treat heavy menstrual bleeding, and has a role in the prevention and treatment of endometrial hyperplasia [1, 3]. In Australia, insertion of LNG-IUDs may be undertaken by specialist obstetricians/gynaecologists, General Practitioners and appropriately trained nurses, in either clinics or hospitals [4].

Use of the LNG-IUD and other IUDs remains low in Australia: limited data suggest that IUDs are used by between 3.2 and $6.1 \%$ of contracepting women, and by as few as $1.7 \%$ of women of reproductive age in Australia and New Zealand [5-7]. Other countries considered to have low uptake at a comparable time period include Germany (5\%) and the United States (5.3\%) [7]. Low uptake in Australia persists despite the LNG-IUD being listed in

(c) The Author(s). 2018 Open Access This article is distributed under the terms of the Creative Commons Attribution 4.0 International License (http://creativecommons.org/licenses/by/4.0/), which permits unrestricted use, distribution, and 
2003 on the Pharmaceutical Benefits Scheme (PBS) which heavily subsidises its cost for Medicare-eligible residents of Australia.

Given its safety and efficacy, there have been calls for efforts to increase use of the LNG-IUD and LARCs in Australia, particularly for young people, among whom rates of unplanned pregnancy and abortion are high $[8$, 9]. Local data indicate LARC use is associated with women's increased age, geographical location and provider-level influences [6,10-12]. Local data are often limited by small sample size, or aggregating LNG-IUDs with other LARCs/ IUDs. Designing and appropriately targeting interventions to increase LNG-IUD use requires knowledge of factors that may be systematically affecting its uptake at the population level. In the absence of reliable population-level measures of uptake, however, population-level prescription rates may be an appropriate substitute. Consequently, we analysed a national dataset of LNG-IUD prescriptions in Australia from 2008 to 2012. Our objectives were to calculate prescribing rates of the LNG-IUD in Australia, determine trends in uptake and associations with patient age, geographical location of the patient and proximity to specialist primary health services that might influence contraception prescription (family planning clinics and Aboriginal medical services).

\section{Methods}

\section{Design \& setting}

This cross-sectional time-series analysis utilises a dataset of the number of prescriptions for the LNG-IUD through the PBS, obtained from the Department of Human Services for the maximum period available which ran from March 2008 to December 2012, inclusive. Prescriptions were recorded according to patient age (5-year cohorts) and residential location, as per standard statistical geography designations used by the Australian Bureau of Statistics. Given that Department of Human Service procedures meant that 2008 records were incomplete, whole-year prescriptions for 2008 were estimated by averaging the prescriptions written for the 10 months recorded and extrapolated across 12 months.

\section{Variables}

Our outcome variable was the number of prescriptions for the LNG-IUD recorded in the PBS dataset.

Covariates included patient age, patient location (rural/ regional/metro), presence of family planning clinics (FPC) at patient location, presence of an Aboriginal medical service (AMS) at patient location, and year of prescription. Patient age-group was measured in 5-year cohorts, from 15 to 49 years of age. Location was measured at Australian Statistical Geography Statistical Area Level 3 (SA3), statistical areas designed to reflect urban and regional areas sharing service centres or characteristics, with populations typically ranging from 30,000 to 130,000: these were assigned to remoteness categories per Australian Bureau of Statistics classifications [13]. The presence of FPCs within an SA3 was included as a binary variable (yes/no): only in WA did the FPCs [2] fall into the same SA3. The presence of Aboriginal medical services within an SA3 was recorded as a categorical variable indicating no service, a regional service, or remote service. Aboriginal medical services in remote areas of Australia are authorised to provide medication through a scheme outside the PBS. Prescription numbers of the LNG-IUD may appear artificially low in these areas, as they are not captured in our data. FPC locations were obtained from the Sexual Health \& Family Planning Australia website [14]. The locations of Aboriginal medical services were identified via the National Aboriginal Community Controlled Health Organisation [15]. Prescription year was included as a linear term.

\section{Statistical analysis}

LNG-IUD prescription rates were calculated, directly age standardised to the estimated resident population (hereafter 'rates') for each year using the population of women aged 15-49 years in Australia as at 30th June 2011 as the standard population [16]. Graphs were used to illustrate observed trends in LNG-IUD prescribing over time according to patient age, remoteness of patient location, and proximity to FPCs and Aboriginal medical services.

Poisson regression was used to examine associations between LNG-IUD prescribing and the covariates, adjusting for potential intra-cluster correlation at SA3 level. Prescriptions for which no SA3 were indicated $(<1.75 \%$ each year $)$ were excluded from regression analyses. Analyses were stratified by age to investigate associations within the different age groups. Analyses were conducted using STATA Version 13 (College Station, TX: StataCorp LP).

\section{Results}

Summary of data and prescriptions

Absolute numbers of prescriptions rose from 60,522 in 2008 to 87,974 in 2012. Age-adjusted rates rose from 11.50 per 1000 women aged 15-49 (95\% CI: 11.41, 11.59 ) in 2008 to 15.95 per 1000 women (95\% CI: 15.95 , $16.01 ; p<0.01$ ) in 2012 (Table 1). Total annual prescribing increased at approximately $9 \%$ per year (RR 1.09; 95\% CI: $1.08,1.09$ ).

\section{Age}

Analysis of prescription data by age shows that prescribing has increased significantly across all age cohorts $(p<$ $0.01)$. Rates were lowest in 15-19-year-olds, at 1.10 per 1000 in 2008 (95\% CI, 0.97-1.24), increasing to 2.76 per 1000 women in 2012 (95\% CI: 2.52-3.01). The absolute 
Table 1 Summary of available prescription data

\begin{tabular}{lllll}
\hline Year & Total prescriptions & Prescriptions missing SA3 (\% total) & Age-adjusted rate (per 1000 women) & $95 \%$ Cl \\
\hline 2008 & 60,522 & $1045(1.73)$ & 11.50 & $11.41,11.59$ \\
2009 & 67,196 & $857(1.28)$ & 12.58 & $12.48,12.67$ \\
2010 & 73,055 & $859(1.18)$ & 13.53 & $13.43,13.63$ \\
2011 & 80,963 & $982(1.21)$ & 14.86 & $14.76,14.96$ \\
2012 & 87,974 & $1045(1.19)$ & 15.95 & $15.85,16.01$ \\
\hline
\end{tabular}

All figures relate to women aged 15-49

increase in prescribing rates was greatest for women 4044 years old, rising from 16.73 per 1000 women in 2008 (95\% CI: $16.12-17.34$ ) to 23.77 per 1000 in 2012 (95\% CI: 22.58-24.29) (Fig. 1a).

Stratified analyses indicate that rate of prescribing increased significantly each year for all age groups, being largest among $15-19$-year-olds at $24 \%$ per year (IRR $=1.24$; $95 \%$ CI: $1.22,1.27$ ) and among $20-24$-year-olds at $16 \%$ per year $($ IRR $=1.16 ; 95 \%$ CI: $1.15,1.18)$. (Table 2$)$ Rate of prescribing increased least among 30-34-year-olds, at 5\% per year $(\mathrm{RR}=1.06$; 95\% CI:1.04, 1.06) (Table 2).

\section{Residential location}

Rates increased significantly within all geographical locations $(p<0.01)$ (Fig. 1b) over time. Prescription rates were significantly higher among 15-34-year-olds not living in major cities (Table 2). Higher rates of prescription were observed among 15-19-year-old women living in very remote areas compared to major cities (RR: $3.01,95 \%$ CI: 1.98-4.58), among 20-24-year-olds (RR: 3.11, 95\% CI: 2.06-4.68) and among 25-29-year-olds (RR: 2.70, 95\% CI:
1.83-3.93). Impact of remoteness decreased with increasing age. Among 35-39-year-olds and 40-44-year-olds, rates of prescribing increased in inner- and outer-regional areas - though to a lesser extent than among younger cohorts - with no significant increase seen in remote and very remote areas. Among 45-49-year-olds, rates were moderately higher in outer-regional areas than in major cities (RR 1.13, 95\% CI: 1.03-1.24) (Table 2).

\section{Proximity to specialist health services}

Although remote locations containing Aboriginal medical services had the lowest prescription rates across all years, these areas showed the greatest increase in number of prescriptions, rising from 8.86 per 1000 women in 2008 (95\% CI: 7.47-10.24) to 15.63 per 1000 women in 2012 (95\% CI: 13.31-17.95) $(p<0.01)$. Absolute rates were similar in locations with no AMS and less remote areas with an AMS (Fig. 1c) $(p<0.01)$. Prescriptions were significantly lower in remote areas with an AMS (RR: 0.62, 95\% CI: 0.43-0.89). Women aged 15-39 years showed significantly lower rates of prescription in remote areas with an AMS, (Table 2).
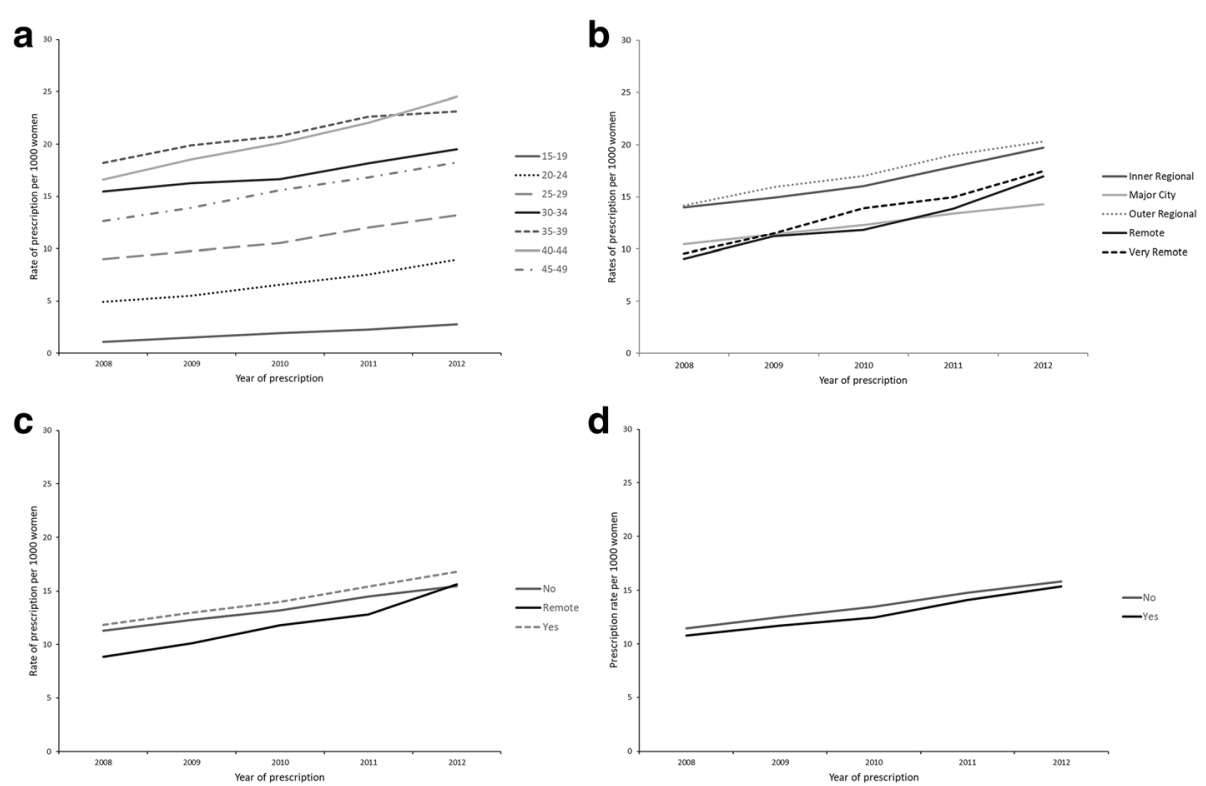

Fig. 1 a Rates of prescription by age cohort. $\mathbf{b}$ Rates of prescription by residential location. $\mathbf{c}$ Rates of prescription by patient proximity to AMS. d Rates of prescription by patient proximity to Family Planning Clinics 


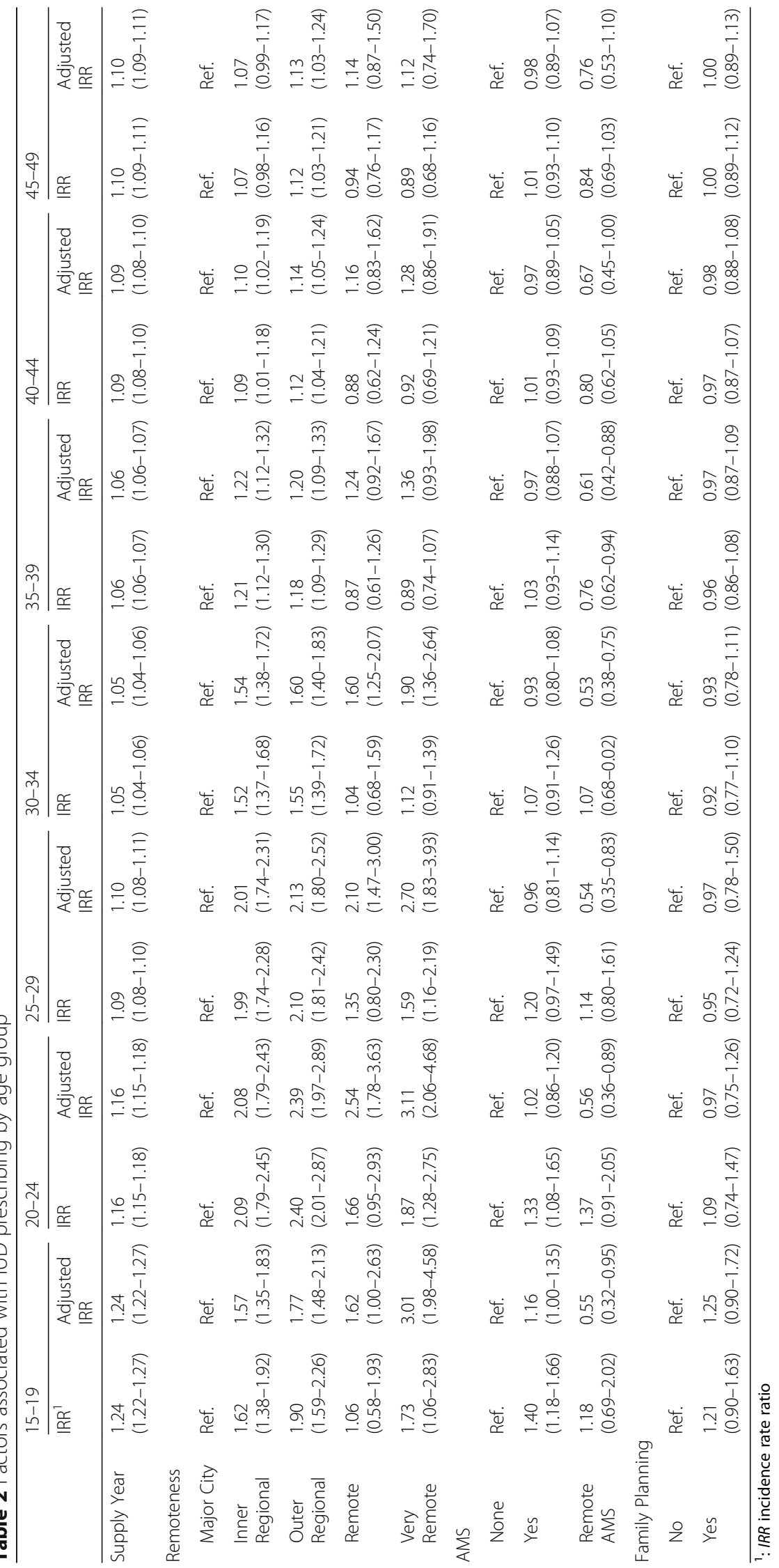


Prescriptions rose at similar rates in locations with and without Family Planning clinics, the former increasing approximately 43\% from 10.76 per 1000 women in 2008 (95\% CI: $9.61-11.91$ ) to 15.37 per 1000 women in 2012 (95\% CI: 13.82-16.92) $(p<0.01)$, while in the latter prescriptions increased approximately 40\% from 11.47 (95\% CI: $11.08-11.86)$ to 15.82 per 1000 women in 2012 (95\% CI: 15.34-16.31) $(p<0.01)$ (Fig. 1d). No significant associations were found between proximity to Family Planning clinics and prescription rates (Table 2).

\section{Discussion}

\section{Prescription of LNG-IUD by age}

Significant disparities exist in prescription of the LNG-IUD across age groups, with prescriptions markedly lower in younger cohorts. Health care providers can influence on women's choice of contraceptive: lower prescriptions for young women may reflect persistent erroneous beliefs among providers about the suitability or otherwise of the LNG-IUD for young and nulliparous women [2, 17-20]. Alternatively, providers may recognise the suitability of LNG-IUD for nulliparous women, but believe its insertion is more complicated for this population, leading them to suggest other forms of contraception [20-22]. While LNG-IUD can be safely inserted in the outpatient setting, New Zealand data suggest that as many as a third of insertions may be undertaken under general anaesthetic, though reasons for doing so could not be assessed in the study [23]. It is possible that a newer, smaller form of the LNG-IUD, marketed internationally as Jaydess or Skyla may be easier to insert in younger/nulliparous women [24]. This device is not currently included on the PBS, nor been marketed locally.

That rates of prescription are increasing more quickly among younger women may reflect recent international attempts to educate providers regarding the safety of IUDs and importance of effective contraception for younger women. Some data also indicate that, having received evidenced-based information regarding contraceptive choices and offered the contraception of their choice free of charge, young women often prefer IUDs [25]. Ensuring that accurate information is available and accessible for young women may contribute to increased demand for, and subsequent prescription of, LARC.

With older women more likely to have had children than younger cohorts, higher rates of prescription of the LNG-IUD in this population may stem at least partly from the lack of these perceived barriers, or from increased demand for LARC from women who have completed their families. Evidence suggests that male and female sterilisations are declining, with the LNG-IUD a potentially contributing factor [4]. Prescription of LNG-IUD to older women may be higher given that the device may additionally be prescribed as a treatment for heavy menstrual bleeding, the incidence of which is associated with increased age [26]. Despite the likelihood of having had children, rates remain relatively low among the 30-34-year age group. While the LNG-IUD is appropriate for use post-partum, and is an effective method for timing pregnancies, prescription patterns in this age group may reflect a lack of knowledge among providers of this practice or barriers such as hospital policy [27].

\section{LNG-IUD prescription and residential location}

We found differences in prescription patterns by patient location, with higher rates of prescription in regional areas compared to major cities. Prescription appears to be increasing in regional and remote areas. It may be that the particular circumstances of regional/rural living are increasing demand for LARC: difficulty in accessing health care, for example, may contribute to a desire for contraception requiring fewer points of contact with the health system. That this increased rate of prescription does not extend to remote areas, despite these populations facing many similar barriers, may indicate a lack of an appropriately trained workforce in remote areas. Analysis of current Family Planning training programs has shown that nurses as well as general practitioners can safely insert the LNG-IUD: this may be one avenue for addressing workforce shortages where necessary [28]. Even with increased accessibility of trained professionals, the relative ease of prescribing oral contraceptives may hinder prescription/insertion of the LNG-IUD - investigating means of incentivising primary care providers to do so may also facilitate uptake.

Prescription differs by geographic location across age groups. Women in regional and remote areas tend to have children at a younger age than their metropolitan counterparts [29]. This may increase the demand for the device in this population as these women have already completed their families. Providers may perceive these parous patients as more suitable candidates for the device, leading to increased prescription of the LNG-IUD. Limited data suggest that rates of hysterectomies, including as a potential treatment for menstrual disorders, may differ by age and urban/rural location: this may affect patterns of LNG-IUD prescription, though further investigation is necessary [30].

Lower rates of prescription were observed in areas with remote AMSs, potentially due to the capacity for some remote AMSs to prescribe outside the PBS system resulting in artificially low prescription numbers. It may also reflect a lack of an appropriately trained workforce in remote regions. Conversely, while no association was found between the presence of FPCs and prescription rates, despite the specialisation of FPCs in reproductive 
health, this may reflect the relatively small number and capacity of FPCs compared to the populations of regions they serve.

\section{Strengths and limitations}

A major strength of this analysis is the use of PBS data, a national-level, administrative dataset which minimises selection and recall bias. However, the dataset has limitations. Data were available until 2012: there may have been a change in prescription patterns since this time, particularly given efforts in recent years to increase uptake. The number and location of FPCs may also have changed during the period analysed.

The data covers only PBS prescriptions, excluding those ineligible for PBS medications, and excludes prescriptions made through organisations which may provide the LNG-IUD outside the PBS through special dispensation regulations. This may affect our interpretation of findings regarding areas with remote AMSs, and potentially of metropolitan areas where prescriptions in hospitals may not be recorded. Whether lower rates of prescription in areas with remote AMSs found here reflect dispensation through these regulations or are indicative of broader barriers to access in remote areas, particularly for indigenous communities, warrants investigation. Examining patterns of prescriptions for the LNG-IUD in hospitals, and whether primary care providers in metropolitan regions are referring women to hospitals for prescription/insertion, may also be informative. While metropolitan prescriptions may appear artificially low in our data, however, the geographic pattern is likely to remain, with greater use of LARCs in rural areas having been identified elsewhere through women's own reported use of contraception [12].

Finally, LNG-IUD may be dispensed through the PBS, but not inserted, meaning that our results reflect prescription of the device rather than uptake.

\section{Conclusions}

Our analysis identified significant differences in patterns of LARC prescription, as a potential indicator of uptake, according to women's age and area of residence. Further research in this area may include similar studies with more recent data, assessment of levels of awareness and accurate knowledge regarding the LNG-IUD in urban versus regional and remote populations at both patient and provider levels and comparisons of levels of provider comfort in LNG-IUD provision and insertion in urban versus rural locations. Identifying the services through which the device is prescribed - e.g. public versus private clinics, or primary care versus hospital-based clinics - may also help the interpretation of results presented here. The availability and accessibility of an appropriately trained workforce, in which settings they operate, and how this may differ across regions, also requires further investigation.

Understanding factors facilitating or constraining LNG-IUD uptake may have important implications for future sexual health and family planning policy, both in Australia and other countries with particularly low uptake of intrauterine contraceptives. Efforts aimed at continuing to increase levels of uptake among younger populations in particular should continue, with providers particularly encouraged to discuss the LNG-IUD with younger patients. However, particularly compared to other countries, there is scope for increased uptake of the LNG-IUD at all ages.

\section{Abbreviations \\ AMS: Aboriginal Medical Service; FPC: Family Planning Clinic; IUD: Intrauterine device; LNG-IUD: Levonorgestrel intrauterine device; PBS: Pharmaceutical Benefits Scheme}

\section{Acknowledgements}

Not applicable.

\section{Funding}

We acknowledge the support of the Brenda Jean Brown Bequest, a private donation to the Gender and Women's Health Unit for use in the field of contraceptive research.

\section{Availability of data and materials}

The data that support the findings of this study are available from Department of Human Services, Australian Government but restrictions apply to the availability of these data, which were used under license for the current study, and so are not publicly available. Data are however available from the authors upon reasonable request and with permission of the Department of Human Services.

\section{Authors' contributions}

$\mathrm{JH}$ conceived the subject matter, obtained data, supervised the analysis and contributed to the paper. CG conceived the subject matter, obtained data and contributed to the paper. $\mathrm{AB}$ collected data, conducted the analysis and contributed to the paper. AK and RB supervised the analysis and contributed to the paper. LK and CB contributed to the paper. All authors read and approved the final manuscript.

Ethics approval and consent to participate Not applicable.

\section{Consent for publication \\ Not applicable.}

Competing interests

The authors declare that they have no competing interests.

\section{Publisher's Note}

Springer Nature remains neutral with regard to jurisdictional claims in published maps and institutional affiliations.

\section{Author details}

${ }^{1}$ Centre for Health Equity, Melbourne School of Population \& Global Health, University of Melbourne, 207 Bouverie Street, Carlton 3010, Australia. ${ }^{2}$ The Royal Women's Hospital, 20 Flemington Road, Parkville, Melbourne, VIC, Australia. ${ }^{3}$ Centre for Epidemiology \& Biostatistics, Melbourne School of Population \& Global Health, University of Melbourne, 207 Bouverie Street, Carlton, Melbourne 3010, Australia. 
Received: 23 November 2017 Accepted: 1 November 2018

Published online: 27 November 2018

\section{References}

1. Stoddard A, McNicholas C, Peipert JF. Efficacy and safety of long-acting reversible contraception. Drugs. 2011;71(8):969-80.

2. National Institute for Health and Care Excellence. Long-acting reversible contraception. In: National Institute for health and care excellence, ed. clinical guidelines; 2014.

3. Fraser IS. Added health benefits of the levonorgestrel contraceptive intrauterine system and other hormonal contraceptive delivery systems. Contraception. 2013;87(3):273-9.

4. Bateson D, Kang $S$, Paterson $H$, Sing K. A review of intrauterine contraception in the Asia-Pacific region. Contraception. 2017;95(1):40-9.

5. Richters J, Grulich AE, de Visser RO, Smith AM, Rissel CE. Sex in Australia: contraceptive practices among a representative sample of women. Aust N Z J Public Health. 2003;27(2):210-6.

6. Eeckhaut MC, Sweeney MM, Gipson JD. Who is using long-acting reversible contraceptive methods? Findings from nine low-fertility countries. Perspect Sex Reprod Health. 2014;46(3):149-55. https://doi.org/10.1363/46e1914 (published Online First: 14 July 2014).

7. Buhling KJ, Zite NB, Lotke $P$, Black K. Worldwide use of intrauterine contraception: a review. Contraception. 2014;89(3):162-73. https://doi. org/10.1016/j.contraception.2013.11.011 (published Online First: 25 November 2013).

8. Sexual Health and Family Planning Australia. Time for a Change: Increasing the Use of Long Acting Reversible Contraceptive Methods in Australia: A Statement from Sexual Health and Family Planning Australia. 2013. http://familyplanningallianceaustralia.org.au/wp-content/uploads/2014/11/ 24448-Family-Planning-A4-Flyer_Proof3.pdf. Accessed 9 Nov 2018.

9. Black Kl, Bateson D, Harvey C. Australian women need increased access to long-acting reversible contraception. Med J Aust. 2013;199(5):317-8.

10. Weisberg E, Bateson D, McGeechan K, Mohapatra L. A three-year comparative study of continuation rates, bleeding patterns and satisfaction in Australian women using a subdermal contraceptive implant or progestogen releasing-intrauterine system. Eur J Contracept Reprod Health Care. 2014;19(1):5-14. https://doi.org/10.3109/13625187.2013.853034.

11. Lucke JC, Herbert DL. Higher uptake of long-acting reversible and permanent methods of contraception by Australian women living in rural and remote areas. Aust N Z J Public Health. 2014;38(2):112-6. https://doi.org/10.1111/1753-6405.12208.

12. Black Kl, Sakhaei T, Garland SM. A study investigating obstetricians' and gynaecologists' management of women requesting an intrauterine device. Aust N Z J Obstet Gynaecol. 2010;50(2):184-8. https://doi.org/10. 1111/j.1479-828X.2010.01136.X.

13. Australian Bureau of Statistics. Australian Statistical Geography Standard (ASGS): Volume 1 - Main Structure and Greater Capital City Statistical Areas. Cat. no: 1270.0.55.001. ACT: Australian Bureau of Statistics; 2011.

14. Sexual Health and Family Planning Australia. http://familyplanningallianceaustralia. org.au/. Accessed 9 Nov 2018.

15. National Aboriginal Community Controlled Health Organisation. https:// www.naccho.org.au/about/naccho-affiliates/. Accessed 9 Nov 2018.

16. Australian Bureau of Statistics. Population estimates by age and sex, Australia by Statistical Geography, 2001 to 2011, data cube: SuperTABLE. Cat. no. 32350.0 [database on the Internet]; 2011. Available online at: http://www.abs.gov.au/ ausstats/abs@.nsf/web+pages/Citing+ABS+Sources\#Data\%20cubes. Accessed 22 Aug 2013.

17. American Congress of Obstetricians and Gynecologists. Adolescents and LongActing Reversible Contraception: Implants and Intrauterine Devices, 2014.

18. Harper CC, Blum M, de Bocanegra HT, et al. Challenges in translating evidence to practice - The provision of intrauterine contraception. Obstet Gynecol. 2008; 111(6):1359-69. https://doi.org/10.1097/AOG.0b013e318173fd83.

19. Committee on Adolescent Health Care Long-Acting Reversible Contraception Working Group. Committee opinion no. 539: adolescents and long-acting reversible contraception: implants and intrauterine devices. Obstet Gynecol. 2012;120(4):983-8.

20. Black K, Lotke $P$, Buhling KJ, Zite NB. A review of barriers and myths preventing the more widespread use of intrauterine contraception in nulliparous women. Eur J Contracept Reprod Health Care. 2012;17(5):340-50. https://doi.org/10. 3109/13625187.2012.700744.
21. Middleton AJ, Naish J, Singer N. General practitioners' views on the use of the levonorgestrel-releasing intrauterine system in young, nulligravid women, in London, UK. Eur J Contracept Reprod Health. 2011;16(4):311-8. https://doi.org/10.3109/13625187.2011.580864.

22. Garrett CC, Keogh LA, Kavanagh A, Tomnay J, Hocking JS. Understanding the low uptake of long-acting reversible contraception by young women in Australia: a qualitative study. BMC Womens Health. 2015;15:72. https://doi. org/10.1186/s12905-015-0227-9.

23. Paterson $\mathrm{H}$, Ashton J, Harrison-Woolrych M. A nationwide cohort study of the use of the levonorgestrel intrauterine device in New Zealand adolescents. Contraception. 2009;79(6):433-8. https://doi.org/10.1016/j. contraception.2008.12.001.

24. Gemzell-Danielsson K, Schellschmidt I, Apter D. A randomized, phase II study describing the efficacy, bleeding profile, and safety of two low-dose levonorgestrel-releasing intrauterine contraceptive systems and Mirena. Fertil Steril. 2012;97(3):616-22.e1-3. https://doi.org/10.1016/j.fertnstert.2011.12.003.

25. Mestad R, Secura G, Allsworth JE, Madden T, Zhao Q, Peipert JF. Acceptance of long-acting reversible contraceptive methods by adolescent participants in the contraceptive CHOICE project. Contraception. 2011;84(5):493-8. https://doi.org/10.1016/j.contraception.2011.03.001.

26. Janssen $\mathrm{CAH}$, Scholten PC, Heintz APM. Menorrhagia-a search for epidemiological risk markers. Maturitas. 1997;28(1):19-25. https://doi.org/10. 1016/S0378-5122(97)00065-0

27. Whaley N, Burke A. Contraception in the postpartum period: immediate options for long-acting success. Women Health. 2015;11(2):97-9.

28. Kemeny $F$, Digiusto $E$, Bateson D. Insertion of intrauterine contraceptive devices by registered nurses in Australia. Aust N Z J Obstet Gynaecol. 2016; 56(1):92-6.

29. AlHW. Rural, regional and remote health: indictaors of health status and determinants of health. Rural Health. Canberra: AlHS; 2008.

30. Spilsbury K, Semmens JB, Hammond I, Block D. Persistent high rates of hysterectomy in Western Australia: a population-based study of 83,000 procedures over 23 years. BJOG. 2006:113:804-9.

Ready to submit your research? Choose BMC and benefit from

- fast, convenient online submission

- thorough peer review by experienced researchers in your field

- rapid publication on acceptance

- support for research data, including large and complex data types

- gold Open Access which fosters wider collaboration and increased citations

- maximum visibility for your research: over $100 \mathrm{M}$ website views per year

At $\mathrm{BMC}$, research is always in progress.

Learn more biomedcentral.com/submissions 